\title{
Exploring the Quality of Life for Saudi Patients Utilizing Dental Healthcare Services: A Systematic Review
}

\author{
Riyadh I Althumairy \\ Division of Endodontics, Department of Restorative Dental Sciences, College of Dentistry, King Saud University, Riyadh, II545, Saudi Arabia \\ Correspondence: Riyadh I Althumairy, Tel +966 I| 4677420, Email ralthumairy@ksu.edu.sa
}

\begin{abstract}
Over three billion people globally are affected by oral diseases. The Kingdom of Saudi Arabia (KSA) has declared a new vision for 2030, which includes an aim to improve the quality of healthcare in the Kingdom while maintaining the efficacy of spending. The Oral Health Impact Profile (OHIP) is a quality of life instrument that helps evaluate health status. This study aims to evaluate equity in accessing dental services and the integration of different types of dental services in the Kingdom of Saudi Arabia. A systematic review of the MEDLINE, ClinicalTrials.gov, and EBSCOhost Research Databases was conducted on August 1, 2021. To answer the research question, the SPIDER search tool that identified the sample, the phenomenon of interest, design, evaluation, and research type prior to conducting the review was adapted. Multiple steps were followed to identify the results. The first step was scanning and selecting the related titles. The second step involved reviewing the abstracts, and the third step involved scanning the full manuscript for all criteria to determine and validate the eligibility of the articles. Twenty-two articles remained in the final stage of the study. The first study applying the OHIP instrument in the KSA was in 2010, and the latest was in 2021. In terms of cities, nine cities accounted for research within eight administrative regions. Of the 4794 patients recruited within these reviewed articles, the highest number of patients reported was 1141 for fashion braces, while the minimum number of patients was 32 for conventional complete dentures. This study shows that the Arabic OHIP tool was successfully adapted by multiple dental studies in the KSA with various dental services and results were reported. The reviewed studies suggest that equity and integration of dental health services are well established in Saudi Arabia. Moreover, the major role of dental academic researchers has been identified.
\end{abstract}

Keywords: OHIP, dental services, KSA, dental integration, dental equity

\section{Introduction}

It has been estimated that over three billion people globally suffer from oral diseases. ${ }^{1}$ Previous studies have shown a correlation between oral diseases and chronic conditions, such as cardiovascular diseases, ${ }^{2}$ chronic obstructive pulmonary disease, ${ }^{3}$ diabetes, kidney disease, ${ }^{4}$ and asthma. ${ }^{5}$ Moreover, dental issues are associated with other health conditions beyond chronic conditions, such as pregnancy-related complications ${ }^{4}$ and low birth weight babies. ${ }^{6}$ Atchison et al suggested that overall health increased when dental care is integrated with medical care. ${ }^{7}$

In the Kingdom of Saudi Arabia (KSA), a national survey estimated that over 1.5 million Saudi adults had a dental routine visit, while over 6.5 million needed a dental service in $2013{ }^{8}$ Studies have suggested that these figures have grown in recent years, which reflects the increased demand for dental services in the Kingdom. ${ }^{9-11}$ Subsequently, the number of dentists per 10,000 population within the Ministry of Health $(\mathrm{MoH})$ has increased from 4.4 in 2016 to 5.6 in 2020. ${ }^{12}$ Certainly, the KSA prioritizes healthcare budget allocation more than other Arab countries. ${ }^{13}$

Because of the increased demand and spending in healthcare, the KSA has declared a new vision for 2030 for various sectors, including healthcare. It aims to improve the quality of healthcare in the Kingdom while maintaining the efficacy of spending. ${ }^{14}$ Quality of life (QoL) is a phrase that has become popular in healthcare for capturing patients' experiences when dealing with medical conditions. ${ }^{15}$ These QoL instruments can be classified as subjective (delivered by patients) or 
objective (delivered by patients' observers). ${ }^{16}$ Another way to categorize QoL measurements is by their goal, where some measurements are generic and similar for all conditions, while other measurements are disease specific and more sensitive to a disease or a service. ${ }^{17}$

Slade and Spencer established the Oral Health Impact Profile (OHIP) as a subjective and oral-specific QoL instrument. ${ }^{18}$ The OHIP consists of seven domains: functional limitation, physical pain, psychological discomfort, physical disability, psychological disability, social disability, and handicap. ${ }^{18}$ Originally, these domains were calculated using 49 questions (OHIP-49); thereafter, Gary Slade modified the OHIP to capture the seven domains using 14 questions to address the nonresponse issue because of the length of the survey. ${ }^{18}$ The OHIP was successfully adapted, translated, and validated in Arabic. ${ }^{19}$

Some studies have explored the QoL for dental services using the Arabic version of OHIP in the KSA; however, these studies focused on a single center with a limited number of patients. Considering the national attention paid to QoL in healthcare, including oral health services, in the KSA, the main goal of this systematic review was to estimate the benefits of quality dental care in Saudi Arabia. To narrow the scope of this goal, the study aimed to a) evaluate equity in accessing dental services in the Kingdom of Saudi Arabia. b) evaluate the integration of different types of dental services in the Kingdom of Saudi Arabia.

\section{Materials and Methods}

A systematic review of the MEDLINE, ClinicalTrials.gov, and EBSCOhost Research Databases (includes: Dentistry \& Oral Sciences Source, MEDLINE Complete, and CINAHL Complete) database was conducted on August 1, 2021. The main research aims were to evaluate equity in accessing dental services and the integration of different types of dental services in the Kingdom of Saudi Arabia; to achieve the aim, the SPIDER search tool described by Cooke et a was used. ${ }^{20}$ The SPIDER search is based on identifying the sample, phenomenon of interest, design, evaluation, and research type prior to conducting the actual review. The details of the SPIDER tool are listed in Table 1.

To make sure the search was efficient and complete, index terms and synonyms for each theme were identified, per recommendation by Bramer. ${ }^{21}$ These themes are summarized in Table 2. Multiple steps were followed to identify the

Table I Definition of Various the SPIDER Tool Elements

\begin{tabular}{|l|l|}
\hline SPIDER & Description \\
\hline Sample & Population from the Kingdom of Saudi Arabia \\
\hline Phenomenon of interest & Dental services \\
\hline Design & Quantitative data (mainly randomized clinical trials, and cohort \& cross-sectional studies) \\
\hline Evaluation & Quality of life through, Equity in Dental Services, Integration of Dental Services \\
\hline Research type & Original article; full article \\
\hline
\end{tabular}

Table 2 Identification of Index Terms and Synonyms for Each Theme

\begin{tabular}{|l|l|}
\hline Terms & Synonyms \\
\hline Saudi Arabia* & KSA; Riyadh; Jeddah; Dammam; Makkah \\
\hline Dental service** & $\begin{array}{l}\text { Dentistry; Oral health; Endo; Dental implantology. Dental implants and tooth restoration; General dentistry; } \\
\text { Maxillofacial surgery; Orthodontics; Pediatric dentistry; Prosthodontics; Cosmetic dentistry; Dental veneers; }\end{array}$ \\
\hline Quantitative data@ & Survey; interview; primary data \\
\hline Quality of life* & QoL; OHIP \\
\hline Original Article@ & Full article; full text \\
\hline
\end{tabular}

Note: *Used in the search box @identified using search filters, if applicable. 


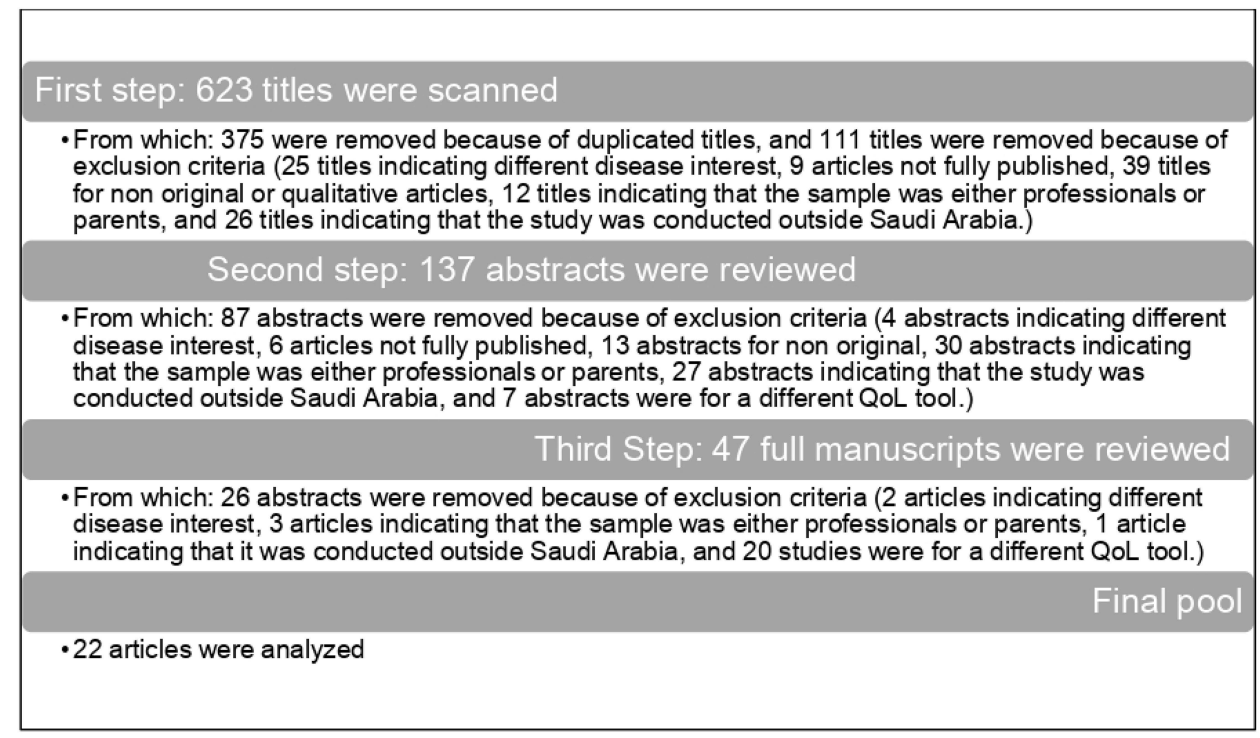

Figure I Illustration of the inclusion and exclusion processes during article selection.

results. The first step was scanning and selecting the related titles that might cover the topic, and duplicated titles were deleted. The second step involved reviewing the abstracts for the key information highlighted in Table 1 . The third step involved scanning the full manuscript for similar criteria to determine and validate the eligibility of the articles. The adaptation of SPIDER tool yielded the following: a sample population from the Kingdom of Saudi Arabia, a phenomenon of interest related to dental service, a design that is based on quantitative data, an evaluation of oral health based on OHIP questionnaire, and an original research.

At any step, the exclusion criteria were as follows: studies focused on different diseases of interest other than dental or oral care, articles that were not published fully, review articles, study sample that did not include patients (and instead had participants such as health professionals, dental students, or parents of patients), articles outside the KSA, qualitative studies, and articles with different QoL tools. Figure 1 illustrates the inclusion and exclusion processes during article selection.

According to the World Health Organization, the benefits of quality health care in general can be realized through different domains: time, equity, integration, and efficiency. ${ }^{22}$ In this review, the focus was on measuring the benefits of dental health care in the KSA by translating equity and integrating dental services from reviewed articles. Equity was captured by estimating the accessibility of oral healthcare in different sites (cities) and times (years) for the local population. ${ }^{23}$ Integration of dental services was captured by accounting for the number of people benefiting (patients) and the type of specialty covered (dental services). Accordingly, each article was classified based on the date of publication, city within the KSA, number of samples, and dental services studied. ${ }^{24}$

\section{Results and Discussion}

Twenty-two articles remained in the final stage of the study. ${ }^{25-46}$ The first study applying the OHIP instrument in the KSA was in 2010, and it is not surprising that researchers continue to use the instrument till date (2021). In terms of cities, ten cities accounted for research within eight administrative regions. Of the 4794 patients recruited within these reviewed articles, the highest number of patients reported was 1141 for fashion braces, while the minimum number of patients was 32 for conventional complete dentures. Table 3 shows the reviewed articles with their affiliated date of publication, cities, number of patients, and dental services utilized.

\section{Equity of Dental Services}

The accessibility of oral healthcare in different cities throughout the years for people living in the KSA were used as indicators of equity of healthcare. In terms of cities, the capital of Saudi Arabia, Riyadh, ${ }^{27-30,44,45}$ accounted for the 
Table 3 Description of the Reviewed Articles

\begin{tabular}{|c|c|c|c|c|}
\hline Authors & Date & City & $\mathbf{N}$ & Dental Services \\
\hline $\begin{array}{l}\text { Khan SD, Alqannass NM, Alwadei MM, Alnajrani MD, Alshahrani ZM, Al } \\
\text { Alhareth AY, Alqahtani } \mathrm{KM}^{25}\end{array}$ & 2021 & Najran & 118 & All dental service utilized \\
\hline Alam, M.K. and Alfawzan, A.A., $2021^{26}$ & 2021 & Not stated & 96 & $\begin{array}{l}\text { Orthodontic patients with ectopic } \\
\text { canine }\end{array}$ \\
\hline $\begin{array}{l}\text { Alrumyyan, A., Quwayhis, S., Meaigel, S., Almedlej, R., Alolaiq, R., } \\
\text { Nafesah, R.B., Almutairi, M. and Alzamil, S., } 2020^{27}\end{array}$ & 2020 & Riyadh & 631 & Fixed dental prostheses \\
\hline Al Deeb, M., Abduljabbar, T., Vohra, F., Zafar, M.S. and Hussain, M., $2020^{28}$ & 2020 & Riyadh & 200 & Removable dental prosthesis \\
\hline $\begin{array}{l}\text { Anbarserri, N.M., Ismail, K.M., Anbarserri, H., Alanazi, D., AlSaffan, A.D., } \\
\text { Baseer, M.A. and Shaheen, R., } 2020^{29}\end{array}$ & 2020 & Riyadh & 152 & Severity of tooth loss \\
\hline Baidas, L.F., AlJunaydil, N., Demyati, M. and Sheryei, R.A., $2020^{30}$ & 2020 & Riyadh & 42 & Fixed orthodontic appliance \\
\hline $\begin{array}{l}\text { Altouki, N.H., Albrahim, M.A., Hassan, A.H., Natto, Z.S. and Alhajrasi, M. } \\
\text { K., } 2020^{31}\end{array}$ & 2020 & Jeddah & 109 & Vertical discrepancies in occlusion \\
\hline Bukhari, O.M., $2020^{32}$ & 2020 & Makkah & 85 & All dental service utilized \\
\hline $\begin{array}{l}\text { Hidayathulla Shaikh, R.H., Fatima, A., Asawa, K., Kannan, K. and Lankar, } \\
\text { A., } 2020^{33}\end{array}$ & 2020 & Al Zulfi & 600 & $\begin{array}{l}\text { Expatriate population dental } \\
\text { quality of life }\end{array}$ \\
\hline Hussein, M.O. and Alruthea, M.S., $2020^{34}$ & 2020 & Qassim & 43 & $\begin{array}{l}\text { Patients treated by mandibular } \\
\text { mini implant overdentures }\end{array}$ \\
\hline $\begin{array}{l}\text { Hakami, Z., Chung, H.S., Moafa, S., Nasser, H., Sowadi, H., Saheb, S. and } \\
\text { Anderson, N.K., } 2020^{35}\end{array}$ & 2020 & Jazan & $|14|$ & Fashion braces \\
\hline $\begin{array}{l}\text { Al Nazeh, A.A., Alshahrani, I., Badran, S.A., Almoammar, S., Alshahrani, } \\
\text { A., Almomani, B.A. and Al-Omiri, M.K., } 2020^{36}\end{array}$ & 2020 & Abha & 50 & $\begin{array}{l}\text { Orthodontic patients treated with } \\
\text { Invisalign clear aligners }\end{array}$ \\
\hline Alqefari, J., Albelaihi, R., Elmoazen, R. and Bilal, R., $2019^{37}$ & 2019 & Qassim & 149 & $\begin{array}{l}\text { Patients undergoing fixed } \\
\text { orthodontic therapy }\end{array}$ \\
\hline $\begin{array}{l}\text { Hassan, A.H., Hobani, N.M., Almokri, S.M., Almokri, N.M., Alotibi, F. } \\
\text { G. and Alshouibi, E.N., } 2018^{38}\end{array}$ & 2018 & Jeddah & 308 & Anterior crowding or spacing \\
\hline Alghamdi, M.A., Farsi, N.J. and Hassan, A.H., $2017^{39}$ & 2017 & Jeddah & 220 & $\begin{array}{l}\text { Patients undergoing orthodontic } \\
\text { treatment }\end{array}$ \\
\hline Ahmad, M.S., Bhayat, A., Zafar, M.S. and Al-Samadani, K.H., $2017^{40}$ & 2017 & $\begin{array}{l}\text { Al Madinah Al } \\
\text { Munawarrah }\end{array}$ & 166 & Hyposalivation \\
\hline AlZarea, B.K., $2017^{4 I}$ & 2017 & Aljouf & 79 & $\begin{array}{l}\text { Implant-supported single crowns } \\
\text { or fixed partial dentures }\end{array}$ \\
\hline Alzarea, B.K., $2016^{42}$ & 2016 & Allouf & 92 & Patients with dental implants \\
\hline Zwiri, A.M., $2015^{43}$ & 2015 & Aljouf & 60 & Recurrent aphthous ulcers \\
\hline Alfadda, S.A., Al-Fallaj, H.A., Al-Banyan, H.A. and Al-Kadhi, R.M., $2015^{44}$ & 2015 & Riyadh & 32 & $\begin{array}{l}\text { Quality of conventional complete } \\
\text { dentures }\end{array}$ \\
\hline AlBaker, A.M., $2013^{45}$ & 2011 & Riyadh & 55 & Conventional complete dentures \\
\hline Hassan, A.H. and Amin, H.E.S., $2010^{46}$ & 2010 & Jeddah & 366 & Orthodontic patients \\
\hline
\end{tabular}


highest number of publications ( 6 articles), followed by Jeddah ${ }^{31,38,39,46}$ (4 articles), followed by AlJouf ${ }^{41-43}$ ( 3 articles). The presence of Riyadh and Jeddah when estimating the frequency of publications is expected, as they account for the first and second most inhabited cities in the KSA. ${ }^{47}$ Both cities have recruited higher number of dentists within the $\mathrm{MoH}$ hospitals. ${ }^{12}$ A surprising result was not to find any article from a city within the Eastern region, specifically Dammam, as it has the fifth highest population density in the Kingdom. ${ }^{47}$ Some studies have explored the QoL for dental services in the Eastern region, but none have used the OHIP tool. This could signal an equity concern, which needs to be explored in the future. The OHIP is derived from Locker's conceptual model of health, which proposed that the impact of oral diseases is ranked by factors (domains) that ultimately impaired the quality of life. ${ }^{18}$ One of the OHIP domains is the handicap domain, which, in the majority of reviewed studies reported that oral health did not impair their quality of life with the exception of two studies. The first was Hassan et al (2010) who reported that when seeking orthodontic treatment in Riyadh, females were significantly more affected than males in term of satisfaction with life in general and were unable to function. The other study was Hakami et al (2020), where they found that in Jazan, there was a significant association between the impairment of QoL and age.

In terms of other equity indicators, time is measured by years of publication. There is an increasing trajectory in the use of the OHIP wherein post 2015 , about $81 \%$ of the articles were published (18 articles), ${ }^{25-42}$ and 2020 in particular accounted for most of these publications (10 articles). ${ }^{27-36}$ This result aligns with the literature on QoL for various healthcare services in Saudi Arabia, where recent publications focused on exploring quality of care among physicians, ${ }^{48}$ pharmacists ${ }^{49}$ and nurses. ${ }^{50}$ Healthcare researchers are expected to apply what has been a governmental goal in improving the quality of care after the launch of the Saudi Vision 2030. ${ }^{14}$ The results prove that dentistry researchers follow a similar path. Indeed, the $\mathrm{MOH}$ in the KSA has launched many initiatives aimed at improving the quality of care. ${ }^{48}$

\section{Integration of Dental Services}

The number of patients within each article and the type of dental service studied were used as parameters for the integration of dental services within the Kingdom. A total of 4794 patients were recruited; the capacity of recruitment was associated with the recruitment site, wherein larger cities, such as Riyadh and Jeddah, yielded a larger number of patients. ${ }^{27,46}$ This is true except in Jazan, where over a thousand patients were studied; one explanation for this is that the researcher was studying a popular type of service-fashion braces. ${ }^{35}$ Moreover, some studies with lower sample sizes may have had methodological challenges that influenced the number of the sample; Hussein and Alruthea conducted a five-year investigation on QoL for selected samples with implant overdentures, ${ }^{34}$ while Alfadda et al explored the QoL of patients with conventional complete dentures, but they needed to determine seven clinical characteristics using three specialized investigators. ${ }^{44}$

In this systematic review, there were different types of dental services covered most frequently: orthodontics $(7$ articles), ${ }^{26,30,35-37,39,46}$ followed by prosthodontics (4 articles), ${ }^{27,28,44,45}$ and implants ( 3 articles). ${ }^{34,41,42}$ The diversity of dental services provides an insight into how well the dental profession is integrated in the Saudi system. Most of the studied articles (16) were conducted in primary dental hospitals in an academic setting. Harnagea et al classified the integration of dental health services with primary care into systemic (macro), organizational and professional (meso), and clinical (micro). ${ }^{51}$ Tailoring similar approach into all types of dental services within the scope of our study would show a clear integration of oral health in the KSA at the macro and meso levels, where currently there are various public dental programs, oral policies, dental education and training, and inter-professional collaboration. Moreover, the fact that most of these reviewed articles were conducted in an academic setting highlights the importance of dental academics in providing dental services and research. Undeniably, research is considered an integral task for academic careers by dental schools both nationally and internationally. ${ }^{52}$

\section{Conclusion}

This study shows that the Arabic OHIP tool was successfully adapted by multiple dental studies in the KSA with various dental services, and results were reported. Despite the wide range of applications of the studied QoL tool, there is a lack of research in the Eastern region. The reviewed studies suggest that equity and integration of dental health services are well established in Saudi Arabia. There is a need for further research to explore the quality of life by the OHIP for certain regions within the kingdom, like Eastern, Ha'il, Jizan, Al-Bahah, Tabuk, and Northern Borders Regions. Moreover, the 
major role of dental academic researchers has been identified. This study is not without limitations, as the article was focused on one type of Questionnaire - OHIP, which limits the generalization of the findings. Other limitations are the fact that this study presented what have been published and focused on defining equity by location, however equity needs boarder definition. Future research can explore equity of dental service in the KSA using other parameters like affordability, quality of oral health services, and gender related access.

\section{Disclosure}

The author reports no conflicts of interest in this work.

\section{References}

1. James SL, Abate D, Abate KH, et al. Global, regional, and national incidence, prevalence, and years lived with disability for 354 diseases and injuries for 195 countries and territories, 1990-2017: a systematic analysis for the global burden of disease Study 2017. Lancet. 2018;392:1789-1858.

2. Park S-Y, Kim S-H, Kang S-H, et al. Improved oral hygiene care attenuates the cardiovascular risk of oral health disease: a population-based study from Korea. Eur Heart J. 2019;40:1138-1145. doi:10.1093/eurheartj/ehy836

3. Scannapieco FA. Individuals with chronic obstructive pulmonary disease (COPD) may be more likely to have more severe periodontal disease than individuals without COPD. J Evid Based Dent Pract. 2014;14:79-81. doi:10.1016/j.jebdp.2014.04.012

4. Kane SF. The effects of oral health on systemic health. Gen Dent. 2017;65:30-34.

5. Gomes-Filho IS, Soledade-Marques KR. Seixas da Cruz S, et al. Does Periodontal Infection Have an Effect on Severe Asthma in Adults?. J Periodontol. 2014;85:e179-187.

6. Corbella S, Taschieri S, Francetti L, De Siena F, Del Fabbro M. Periodontal disease as a risk factor for adverse pregnancy outcomes: a systematic review and meta-analysis of case-control studies. Odontology. 2012;100:232-240. doi:10.1007/s10266-011-0036-z

7. Atchison KA, Weintraub JA, Rozier RG. Bridging the dental-medical divide: case studies integrating oral health care and primary health care. $J \mathrm{Am}$ Dent Assoc. 2018;149:850-858. doi:10.1016/j.adaj.2018.05.030

8. El Bcheraoui C, Tuffaha M, Daoud F, et al. Use of dental clinics and oral hygiene practices in the kingdom of Saudi Arabia, 2013. Int Dent J. 2016;66:99-104.

9. Almutlaqah MA, Baseer MA, Ingle NA, Assery MK, Al Khadhari MA. Factors affecting access to oral health care among adults in Abha City, Saudi Arabia. J Int Soc Prev Community Dent. 2018;8:431. doi:10.4103/jispcd.JISPCD_205_18

10. Al-Jaber A, Da'ar OB. Primary health care centers, extent of challenges and demand for oral health care in Riyadh, Saudi Arabia. BMC Health Serv Res. 2016;16:1-8. doi:10.1186/s12913-016-1876-6

11. Quadri FA, Jafari FAM, Albeshri ATS, Zailai AM. Factors influencing patients' utilization of dental health services in Jazan, kingdom of Saudi Arabia. Int J Clin Pediatr Dent. 2018;11:29. doi:10.5005/jp-journals-10005-1479

12. Ministry of Health. Statistical yearbook 2020 - Chapter II: Health Resources; 2020. Available from: https://www.moh.gov.sa/en/Ministry/Statistics/ book/Pages/default.aspx. Accessed August 3, 2021.

13. World Health Organization. Saudi Arabia Health expenditure profile. Global health expenditure database; 2016. Available from: https://apps.who. int/nha/database/DocumentationCentre/GetFile/57490611/en. Accessed August 3, 2021.

14. Alharbi MF. An analysis of the Saudi health-care system's readiness to change in the context of the Saudi national health-care plan in vision 2030. Int J Health Sci. 2018;12:83.

15. Gureje O, Oladeji B. Mental health, morbidity and impact. In: International Encyclopedia of Public Health. Singapore Academic Press. 2017:73-80.

16. Davis E, Young D, Waters E, Gold L. Measuring the quality of life of children and adolescents. In: Quah Sr, editor. Reference Module in Biomedical Sciences. Oxford: Academic Press; 2016:539-545.

17. Rascati KL. Essentials of Pharmacoeconomics. Baltimore: Lippincott Williams \& Wilkins; 2008:250.

18. Anagnostopoulos F. Oral health impact profile. In: Michalos AC, editor. Encyclopedia of Quality of Life and Well-Being Research. Dordrecht: Springer Netherlands; 2014:4506-4510.

19. Al-Jundi MA, Szentpétery A, John MT. An Arabic version of the oral health impact profile: translation and psychometric properties. Int Dent J. 2007;57:84-92. doi:10.1111/j.1875-595X.2007.tb00443.x

20. Cooke A, Smith D, Booth A. Beyond PICO: the SPIDER tool for qualitative evidence synthesis. Qual Health Res. 2012;22:1435-1443. doi: $10.1177 / 1049732312452938$

21. Bramer WM, de Jonge GB, Rethlefsen ML, Mast F, Kleijnen J. A systematic approach to searching: an efficient and complete method to develop literature searches. J Med Libr Assoc. 2018;106:531. doi:10.5195/jmla.2018.283

22. World Health Organization. Quality of care; 2021. Available from: https://www.who.int/health-topics/quality-of-care\#tab=tab_1. Accessed August 3, 2021.

23. Watt RG, Williams DM, Sheiham A. The role of the dental team in promoting health equity. Br Dent J. 2014;216:11-14. doi:10.1038/sj. bdj.2013.1234

24. Atchison KA, Rozier RG, Weintraub JA. Integration of oral health and primary care: communication, coordination and referral. NAM Perspect. 2018. doi:10.31478/201810e

25. Khan SD, Alqannass NM, Alwadei MM, et al. Assessment of the relationship between dental anxiety and oral health-related quality of life. J Pharm Bioallied Sci. 2021;13:359. doi:10.4103/jpbs.JPBS_742_20

26. Alam MK, Alfawzan AA. Oral health impact profile in orthodontic patients with ectopic canine: a prospective clinical intervention of four treatment modalities. Healthcare. 2021;9:337. doi:10.3390/healthcare9030337 
27. Alrumyyan A, Quwayhis S, Meaigel S, et al. Oral health-related quality of life and oral hygiene practice of adults with fixed dental prostheses in Riyadh, Saudi Arabia. J Int Soc Prev Community Dent. 2020;10:62.

28. Al Deeb M, Abduljabbar T, Vohra F, Zafar MS, Hussain M. Assessment of factors influencing oral health-related quality of life (OHRQoL) of patients with removable dental prosthesis. Pakistan J Med Sci. 2020;36:213.

29. Anbarserri NM, Ismail KM, Anbarserri H, et al. Impact of severity of tooth loss on oral-health-related quality of life among dental patients. $J$ Fam Med Prim Care. 2020;9:187. doi:10.4103/jfmpc.jfmpc_909_19

30. Baidas LF, AlJunaydil N, Demyati M, Sheryei RA. Fixed orthodontic appliance impact on oral health-related quality of life during initial stages of treatment. Niger J Clin Pract. 2020;23:1207. doi:10.4103/njcp.njcp_681_19

31. Altouki NH, Albrahim MA, Hassan AH, Natto ZS, Alhajrasi MK. Oral health-related quality of life of Saudi young adults with vertical discrepancies in occlusion. Patient Prefer Adherence. 2020;14:1021. doi:10.2147/PPA.S235141

32. Bukhari OM. Dental caries experience and oral health related quality of life in working adults. Saudi Dent J. 2020;32:382-389. doi:10.1016/j. sdentj.2019.11.003

33. Hidayathulla Shaikh RH, Fatima A, Asawa K, Kannan K, Lankar A. Assessment of oral health-related quality of life among expatriate working population, Saudi Arabia: a cross-sectional study. J Int Soc Prev Community Dent. 2020;10:504. doi:10.4103/jispcd.JISPCD_149_20

34. Hussein MO, Alruthea MS. Marginal bone level changes and oral health impact profile (14) score of smokers treated by mandibular mini implant overdentures: a 5-year follow-up study. Eur J Dent. 2020;14:590-597. doi:10.1055/s-0040-1714763

35. Hakami Z, Chung HS, Moafa S, et al. Impact of fake braces on oral health related quality of life: a web-based cross-sectional study. BMC Oral Health. 2020;20:236. doi:10.1186/s12903-020-01224-1

36. Al Nazeh AA, Alshahrani I, Badran SA, et al. Relationship between oral health impacts and personality profiles among orthodontic patients treated with Invisalign clear aligners. Sci Rep. 2020;10:1-12. doi:10.1038/s41598-020-77470-8

37. Alqefari J, Albelaihi R, Elmoazen R, Bilal R. Three-dimensional assessment of the oral health-related quality of life undergoing fixed orthodontic therapy. J Int Soc Prev Community Dent. 2019;9:72.

38. Hassan AH, Hobani NM, Almokri SM, Almokri NM, Alotibi FG, Alshouibi EN. Effect of anterior crowding or spacing on oral health-related quality of life: a cross-sectional study. Patient Prefer Adherence. 2018;12:461. doi:10.2147/PPA.S149081

39. Alghamdi MA, Farsi NJ, Hassan AH. Comparison of oral health-related quality of life of patients treated by palatal expanders with patients treated by fixed orthodontic appliances. Patient Prefer Adherence. 2017;11:699. doi:10.2147/PPA.S124519

40. Ahmad MS, Bhayat A, Zafar MS, Al-Samadani KH. The impact of hyposalivation on quality of life (QoL) and oral health in the aging population of Al Madinah Al Munawarrah. Int J Environ Res Public Health. 2017;14:445. doi:10.3390/ijerph14040445

41. AlZarea BK. Oral health related quality-of-life outcomes of partially edentulous patients treated with implant-supported single crowns or fixed partial dentures. J Clin Exp Dent. 2017;9:e666.

42. Alzarea BK. Assessment and evaluation of quality of life (OHRQOL) of patients with dental implants using the oral health impact profile (OHIP-14)-A clinical study. J Clin Diagnostic Res. 2016;10:ZC57.

43. Zwiri AM. Anxiety, depression and quality of life among patients with recurrent aphthous ulcers. J Contemp Dent Pr. $2015 ; 16: 112-117$. doi:10.5005/jp-journals-10024-1646

44. Alfadda SA, Al-Fallaj HA, Al-Banyan HA, Al-Kadhi RM. A clinical investigation of the relationship between the quality of conventional complete dentures and the patients' quality of life. Saudi Dent J. 2015;27:93-98. doi:10.1016/j.sdentj.2014.10.003

45. AlBaker AM. The oral health-related quality of life in edentulous patients treated with conventional complete dentures. Gerodontology. 2013;30:61-66. doi:10.1111/j.1741-2358.2012.00645.x

46. Hassan AH, Amin HE-S. Association of orthodontic treatment needs and oral health-related quality of life in young adults. Am J Orthod Dentofac Orthop. 2010;137:42-47. doi:10.1016/j.ajodo.2008.02.024

47. General Authority for statistics. Number of inhabitants in cities with a population greater than (5000) people; 2010. Available from: https://www. stats.gov.sa/sites/default/files/census31-prim-05.pdf. AccessedAugust 3, 2021.

48. Alasmari S, Williams S, Rich N, Rea D. Sustainability of quality improvement initiatives within the Saudi Ministry of Health hospitals: an institutional overview. Saudi J Heal Syst Res. 2021;1:3-10. doi:10.1159/000514179

49. Althemery A. Application of the EQ-5D in the Middle East: a systematic review focusing on patients living in the Kingdom of Saudi Arabia. $J$ Multidiscip Healthc. 2021;14:1101. doi:10.2147/JMDH.S306703

50. Albaqawi HM. Quality nursing work life among nurses in Hail Region, Kingdom of Saudi Arabia: redefining the boundaries of work and life. Adv Soc Sci Res J. 2018;5. doi:10.14738/ASSRJ.53.4341

51. Harnagea H, Lamothe L, Couturier Y, et al. From theoretical concepts to policies and applied programmes: the landscape of integration of oral health in primary care. BMC Oral Health. 2018;18:1-12. doi:10.1186/s12903-018-0484-8

52. Roger JM, Wehmeyer MMH, Milliner MS. Reflections on academic careers by current dental school faculty. J Dent Educ. 2008;72:448-457. doi:10.1002/j.0022-0337.2008.72.4.tb04510.x

Journal of Multidisciplinary Healthcare

Dovepress

\section{Publish your work in this journal}

The Journal of Multidisciplinary Healthcare is an international, peer-reviewed open-access journal that aims to represent and publish research in healthcare areas delivered by practitioners of different disciplines. This includes studies and reviews conducted by multidisciplinary teams as well as research which evaluates the results or conduct of such teams or healthcare processes in general. The journal covers a very wide range of areas and welcomes submissions from practitioners at all levels, from all over the world. The manuscript management system is completely online and includes a very quick and fair peer-review system. Visit http://www.dovepress.com/testimonials.php to read real quotes from published authors.

Submit your manuscript here: https://www.dovepress.com/journal-of-inflammation-research-journal

Journal of Multidisciplinary Healthcare 2022:15

$f y$ in $\rightarrow$ DovePress 